\title{
PEDRO PARICIO. EL PINTOR \\ QUE SE HACE CAMINO AL PINTAR*
}

\author{
Carmen Milagros González Chávez
}

\section{RESUMEN}

En este artículo presentamos a un pintor canario con reconocimiento a nivel mundial. Pedro Paricio reivindica la pintura como oficio de su vida. Se alimenta de la tradición pictórica para crear una pintura pura, formalmente contemporánea, rica en color y, sobre todo, honesta y hasta trascendental. El pintor recurre a la abstracción y a la figuración para expresar su mundo interior, sus anhelos e inquietudes, inscribiéndose de esta manera en la línea de aquellas manifestaciones artísticas del pasado que utilizaron, especialmente, el color, como vehículo de expresión.

PALABRAS ClAVE: pintura, tradición, formalmente contemporánea, color.

\author{
PEDRO PARICIO. THE PAINTER'S ROAD \\ IS DONE WHEN PAINTING
}

\section{Abstract}

In this article we present a famous canarian artist known in the world wide. Pedro Paricio reclaim the paint as the model of life. He feeds with the pictorial tradition to create a pure pictures in a conteporary way using vivid colours and expressing feelings. The painter appeal to the abstraction and the figuration to show his inside world, yearnings, and anxieties registering in this way in the line of those manifestations of the past that they used in a specific way, the color as a vehicle of expression.

KEYWORDS: paint, tradition, contemporary, colour. 
Color y líneas, imaginación y estructuración, abstracción y figuración, tradición y modernidad son los binomios que definen la práctica artística de Pedro Paricio, un pintor canario (Tenerife, 1982) con reconocido prestigio no solo en los círculos nacionales (exposiciones en Salamanca, Barcelona, Madrid, Valencia, Sevilla y Santa Cruz de Tenerife), sino también a nivel internacional (Europa, EE.UU. y América Latina).

Comenzó a estudiar pintura en Tenerife, continuó en Salamanca, se licenció en Barcelona y, allí, en 2008, fue descubierto por la Halcyon Galery de Londres, galería que, como ocurriera en el pasado con el salón oficial y los grandes maestros de la pintura, sirvió de trampolín a la «fama» y al mercado de arte mundial; en palabras del artista, fue y es una ventana al mundo ${ }^{1}$.

Paricio se define como un pintor con vocación, un artista que hace del oficio de la pintura el oficio de su vida: «hay que volver al taller a dejarse la vida sobre el lienzo». Antes de conseguir esta meta, tuvo numerosos trabajos como animador de fiestas infantiles, repartidor... Tenía que sobrevivir, hasta que se decantó por la pintura: «tengo fe en la pintura. Considero que la pintura es infinita y mi fe en ella también es infinita».

En el panorama del arte contemporáneo, apostar por la pintura, sin un mercado asegurado y cuando algunos han pronosticado el agotamiento y la muerte de la misma, parece todo un reto que, en este caso, revela el carácter indómito y rebelde del artista. Paricio parece nadar a contracorriente: me interesa, la propia pintura, porque en lugar de inclinarse hacia un arte que comulga con las tecnologías recientes (internet, videoarte, instalaciones multimedia...) defiende una pintura pura, libre de toda preocupación comercial, auténtica, honesta y hasta trascendental.

Sus composiciones resultan tan envolventes como los montajes digitales, pero no recurre ni a proyecciones, sonidos, videoarte, experiencias interactivas... $\mathrm{Al}$ contrario, con los recursos de la pintura, con las formas y los colores, con linos y pigmentos, crea obras tan sugerentes que nos invitan a dialogar, «la pintura de manera muy simple es capaz de evocar muchas cosas». Sus cuadros son ventanas abiertas. El espectador debe participar leyendo, cuestionando y hasta emocionándose ante el cuadro. La obra de arte, nos dice el pintor, «es cosa de tres: el artista que la crea, la obra que se independiza y el espectador que con sus miradas y reflexiones la revitaliza».

Desde el principio sus obras presentan como tema sus propias vivencias. La evolución pictórica del artista es la propia de la madurez del hombre, que, con la lectura, el trabajo continuo, el contacto con otros artistas y críticos, el viaje, la visita a exposiciones... se reafirma en su discurso.

Se ha escrito que hay dos etapas diferenciadas en su corta carrera: una primera abstracta y una evolución hacia la figuración. El artista replica que en su

* Paricio, Pedro: Textos inconclusos, Galería Fidel Balaguer, Barcelona, 2010, p. 37.

1 Todas las citas en cursivas pertenecen a Pedro Paricio. Entrevista realizada por la autora del artículo al pintor en su estudio/taller en La Orotava, entre enero y febrero de 2018. 


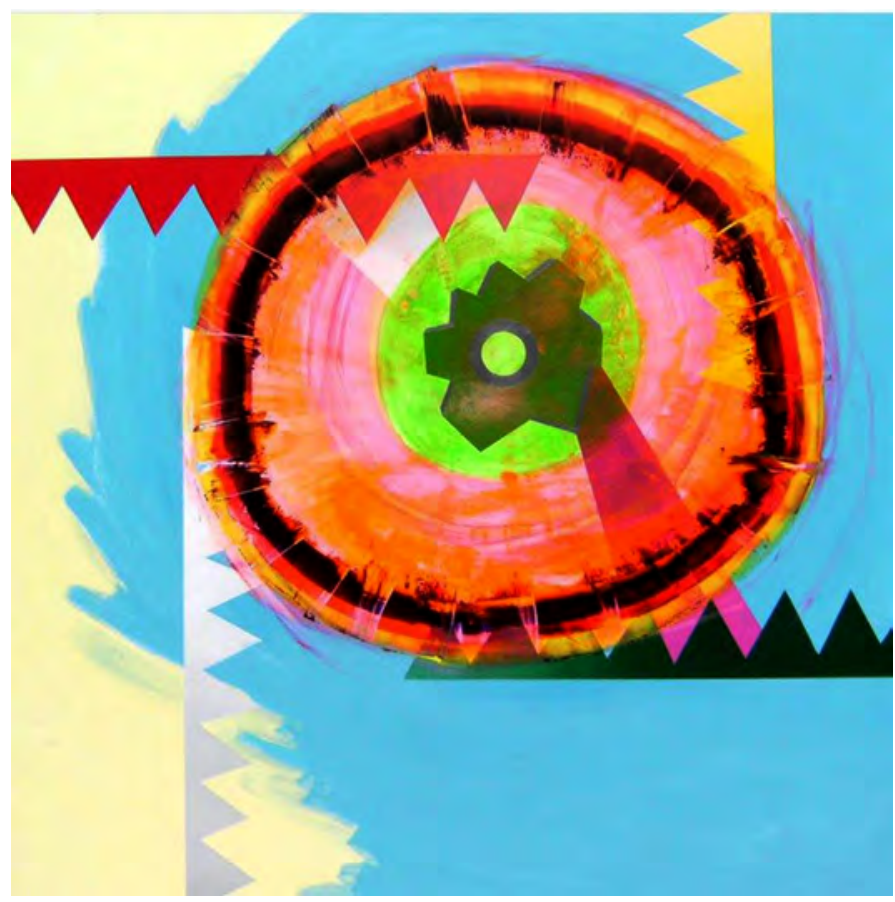

Imag. 1. Envergadura. Serie Size Me, 2010.

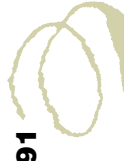

caso abstracción y figuración no pueden desvincularse, que posiblemente en las primeras series pintadas recurría a la figuración abstracta y en las más recientes, a la abstracción figurativa, pero en cualquier caso, la narrativa es evidente, aunque más metafórica al principio y más real y concreta, en las últimas. El pintor nos recuerda:

Soy abstracto pero también figurativo, soy narrativo a la vez que poético, soy compositivo a la vez que desectructuralista. Lo único que soy capaz de contestar es que me siento un pintor colorista que se inscribe en la línea de Van Gogh, Gauguin, Matisse, Bacon, Rothko, Barceló...².

En este breve artículo nos limitaremos a presentar de forma muy somera al artista, recurriendo solamente a dos lienzos, uno más abstracto y otro más figurativo, pero en ambos implícitas su personalidad porque reclama estas expresiones artísticas para comunicar, como hacían los románticos, simbolistas, expresionistas y surrealistas, sus pensamientos, inquietudes y anhelos.

2 «Pedro Paricio. Un pintor otro», en Artsmoved. Entrevista, agosto 2010. (Consultado el 30 de enero de 2018 en http://www.artsmoved.cat/es/pedro-paricio-un-pintor-otro/). 


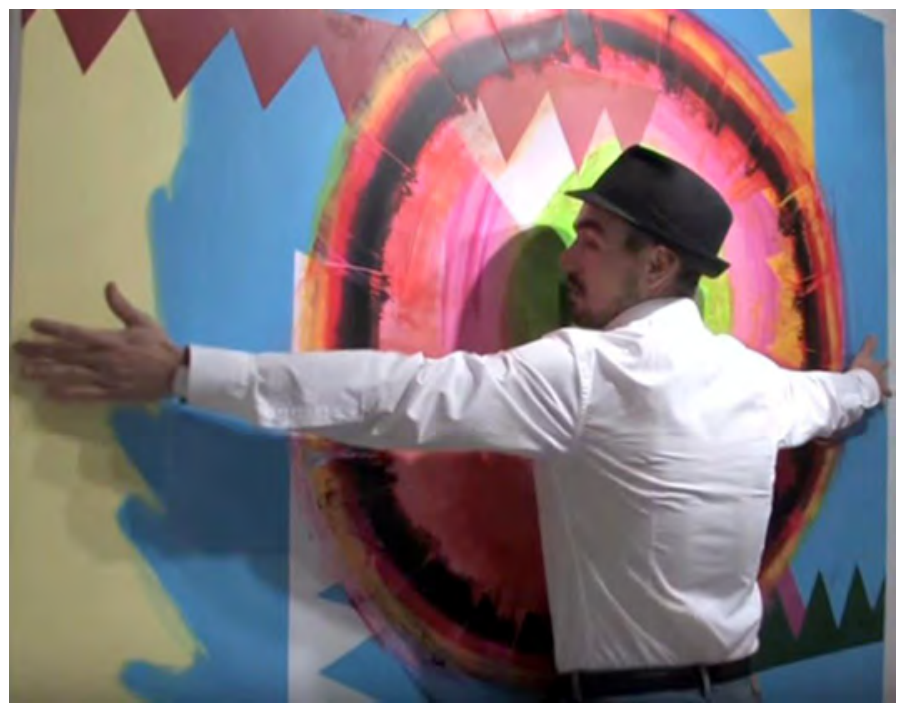

Imag. 2. Pedro Paricio delante de Envergadura. Serie Size Me, 2010.

Comenzamos mencionando la obra Envergadura, perteneciente a la serie Size Me, expuesta en la galería Fidel Balaguer en 2010. En esta colección no hay autorretratos propiamente dichos del pintor, pero las formas, colores y líneas están reducidas a un formato que reproduce sus medidas físicas (altura, sus manos, sus piernas...) y se convierten en el traje de pintor.

Algo tan prosaico como el tamaño de los lienzos, en la obra de Paricio se convierte en algo más personal. El lienzo que mencionamos, Envergadura, de rico colorido, tiene las dimensiones del artista con los brazos y piernas extendidas. También, sus manos y sus pies son motivos para crear dípticos que se resuelven con su discurso colorido.

El artista habla que el traje de la pintura esconde su propia esencia. Paricio, que es un pintor intuitivo y de sentimientos, no repara en el uso de figuras geométricas y de las leyes físicas de los contrastes de colores. El círculo es la figura geométrica por excelencia: principio y fin. Vitrubio y Leonardo lo utilizaron para representar al hombre como medida y centro del universo. Aquí, el pintor se coloca delante del círculo, él es el centro de su pintura y la pintura es el centro de su vida. Igualmente, aparecen los triángulos, símbolo de la suma perfección, que se traducen en una obra bien acabada, que lo estará «cuando el pintor, psicológica y no físicamente, es capaz de sentir y decidir que está finalizada».

Asimismo, hace uso de diversos colores que van desde del verde hasta el rojo, completándose con el azul y el amarillo. Sin premeditación, ha empleado los tonos con sus complementarios, como ya hacían los pintores impresionistas, buscando dotar al cuadro de intensa luminosidad. Y esa luz no es otra que la que penetra en su visión desde la infancia, la luz de Canarias. 


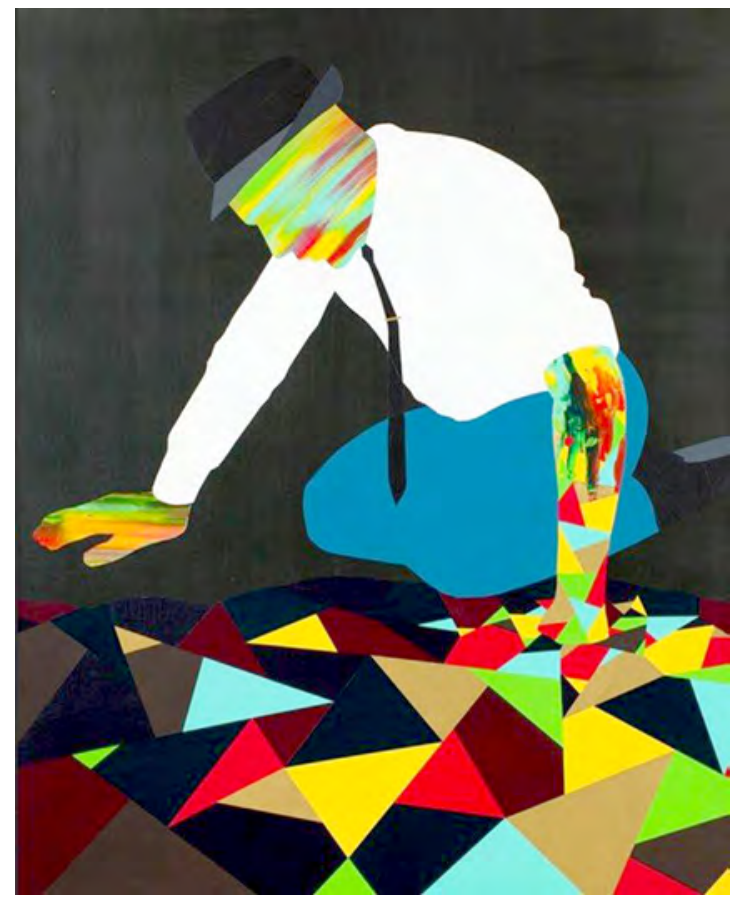

Imag. 3. I am painting. Serie Diary of an artist, 2011.

Son autorretratos atípicos pero que nos hablan de que la pintura es el centro de su universo, que sus cuadros son monólogos y diálogos, sobre y con la pintura. Trata de reivindicar que la pintura debe hablar sobre uno mismo.

Cuando la abstracción figurativa parece apropiarse de sus lienzos, Paricio es el protagonista. Se autorretrata con frecuencia. Comentaremos uno de los más significativos. Me refiero a I am painting, traducido como Estoy pintando o Yo soy pintura, perteneciente a la serie de Diary of an artist, en 2011. Utiliza el idioma inglés para titular sus obras porque le permite jugar con las palabras. Esta colección recoge a través de lienzos las actividades propias del pintor, el día a día: ducharse, tomar el sol, referencias al deporte, enamorarse, cansancio al final de la jornada. Su lenguaje está más cercano a la figuración pero la abstracción está presente, y siempre en clave poética.

Sobre un fondo negro, aparece representada su figura, adoptando la pose que Narciso, según la leyenda y la tradición pictórica -Caravaggio, Poussin-, adopta al contemplarse reflejado en el agua. La pintura es muy rica en sugerencias.

Podríamos identificar al pintor con el semidiós pagano, y concebirlo como arrogante y con una excesiva consideración de sí mismo. Todo lo contrario: Paricio nos seduce y manipula porque reinterpreta la historia para hablarnos de la honestidad. Recurre a grandes maestros con los que dialoga a través de la pintura pero, 
pensando en ellos, es capaz de hacer algo completamente diferente. Reivindica la abstracción figurativa y nos muestra una figura a base manchas de color plano, sin los rasgos de la cara; las manos, sin dedos; las ropas sin pliegues, pero figurativa, a la que añade una superficie geometrizante de triángulos de ricos colores que remplaza las aguas cristalinas del mito.

Se nos muestra con una indumentaria que se convertirá en una constante, camisa blanca, pantalón azul y dos complementos negros: el sombrero y la delgada corbata. Se añaden manchas de colores contrastados para la cara y las manos, una de ellas se prolonga hasta fundirse con una superficie abstracta. Cabeza, manos y lienzo, unidos por el color, en un claro ejercicio de automatismo. Colores vivos que como dirá Paricio hablan de su personalidad positiva, recordemos que la segunda traducción del título podría ser Yo soy pintura.

Este cuadro nos hace también reflexionar en una constante de su trayectoria pictórica, la reivindicación de la tradición en la pintura. Es un joven pintor que no detesta el pasado, como ha demostrado en sus series Master Painters, 2011, y en The spirit of painting, 2013. Valora, aprende y se apropia de los grandes maestros de la pintura: Velázquez, Caravaggio, Poussin, Goya, Manet, Van Gohg, Klimt, Picasso, Warhol... «los trae al presente y los trabaja para el futuro». Llega a decir: "tengo 40000 años de historia de la pintura para usar y quiero aprovecharlos todos, pero a mi manera».

Decía el poeta Paul Valery que la auténtica tradición en las grandes obras no estriba en rehacer lo que otros han creado, sino en reencontrar su espíritu, que crea obras nuevas en otro tiempo. Y es este precisamente el diálogo que sostiene nuestro pintor con los grandes maestros del pasado para crear obras de arte, bien acogidas por la crítica y los coleccionistas privados, obras frescas, evocadoras y contemporáneas, que invitan al espectador a reflejarse en ellas y a recomponer el código pictórico que ha usado el artista para comunicarse.

Pedro Paricio nos dice que un cuadro no debe explicarse, «es un hecho absurdo, el cuadro que se puede explicar, mejor no haberle pintado». Nos atrevemos, pues, a leer y sugerir lecturas de sus obras, que se suman a las intenciones evocadas por el pintor. 